\title{
Near Infrared Raman Spectroscopy (NIRS): A technique for doping control
}

\author{
A.E. Guimarães, M.T.T. Pacheco, L. Silveira Jr. *, D. Barsottini, J. Duarte, A.B. Villaverde and \\ R.A. Zângaro \\ Institute of Research and Development (IP\&D), Universidade do Vale do Paraíba (UNIVAP), \\ Av. Shishima Hifumi, 2911, Urbanova, São José dos Campos, ZIP 12244-000, SP, Brazil
}

\begin{abstract}
This paper reports the application of near-infrared Raman spectroscopy to detect ephedrine in biological medium. At present time, the doping control for ephedrine in athletes uses the urinalysis by the gas chromatography/mass spectrometry, with main disadvantage the need of collecting urine and the time delay to obtain results. This work aims to develop a noninvasive technique that will allow to evaluate the concentration of the ephedrine in a real time diagnosis. A Raman system composed by a Ti:Saphire laser pumped by an Argon laser was used, operating at the wavelength of $785 \mathrm{~nm}$, with a laser power of $70 \mathrm{~mW}$ at sample position. Raman scattered photons were collected by a f/l.8 spectrometer and a $\mathrm{N}_{2}$-cooled CCD detector. Ephedrine Raman peaks at 1002 and $1603 \mathrm{~cm}^{-1}$ were studied, opening possibility for the identification and quantification of ephedrine. Raman spectra of ephedrine with different concentrations in human urine were taken, and the intensity of the ephedrine peak at $1002 \mathrm{~cm}^{-1}$ was measured as a function of its concentration. It was also studied the Raman spectrum of an urine sample from a Wistar rat, after a subcutaneous inoculation of an ephedrine solution in physiologic serum, at the concentration of $5 \mathrm{mg} / \mathrm{ml}$. It was found that Raman spectroscopy could detect ephedrine in urine at concentrations lower than the doping limit legally permitted by the International Olympic Committee.
\end{abstract}

Keywords: Near-infrared Raman spectroscopy, doping control, ephedrine, noninvasive diagnosis

\section{Introduction}

The ephedra alkaloids have received recently more attention because of their widespread use by athletes and their potentially severe side effects. They are being used despite of lack of evidence regarding any ergogenic or performance benefit. There are some prescription drugs (methylphenidate and bupropion) that contains ephedrine in their formula; because of that, the therapeutic use of those drugs by athletes is questionable [1].

Currently, the doping control for ephedrine is based on the urinalysis by gas chromatography/mass spectrometry test [2-5]. The urinalysis technique is a very important technique for doping control in sports, mainly because of the longer time decay. In blood, most of the abused drugs, including their metabolites, decay to low levels after a few hours from drug uptake, while urine samples generally have a longer surveillance time of about $1-3$ days $[4,5]$. The routine urinalysis examination presents as disadvantages the need of material collection and the time delay to obtain the assay results, estimated to be as long as 24 hours.

\footnotetext{
${ }^{*}$ Corresponding author: Prof. Landulfo Silveira Junior, Institute of Research and Development (IP\&D), Universidade do Vale do Paraíba (UNIVAP) Av. Shishima Hifumi, 2911 - Urbanova - São José dos Campos 12244-000, SP, Brazil. Tel.: +155 123947 1124; Fax: +155 123947 1149; E-mail: landulfo@univap.br.
} 
The investigation for a non-invasive technique to detect blood metabolites have been conducted by many researches along last decades. Most of the efforts were directed to solve the important issue of glucose testing for diabetics [6-9]. At the present time, there have been works reporting the use of optical tools such as laser-induced fluorescence [10] and Raman spectroscopy to study ephedrine molecules [11, 12]. There is a continuous search for an on-line method that can be used to characterize bio-analytes and metabolites. The ideal method should be one that can be performed in real time, less invasively, less painful precise, and low cost [13], and the dispersive, near-infrared Raman spectroscopy (NIRS) technique now is proposed.

Among different techniques, the NIRS is a very promising since it can be easily applied to analyze biological fluids. For instance, Pilloto et al. [14] identified the presence of lactic acid in human serum and blood from a Wistar rat, in vitro and in vivo, through NIRS, confirming the possibility to use this technique as a noninvasive and effective method of blood diagnosis.

The Raman scattering effect is an inelastic process that occurs when a sample is illuminated with a strong monochromatic light source (such as a laser beam). In this process, energy from the incident photons is transferred to the sample molecules, exciting them to high vibrational modes. Scattered photons have a lower frequency than the incident ones due to the energy transfer, that is lost in the scattering process. The frequency shift of the excitation radiation corresponds to the different vibrational frequencies of the molecules of the sample material. Thus, a Raman spectrum helps one to determine the composition of the sample, since each molecule has its own characteristic Raman spectrum. The Raman spectroscopy using near-infrared radiation has the advantage that the radiation penetrates deeper into the biological tissues and the sample fluorescence is lower.

The emission lines in the Raman effect are sharp spectroscopically well resolved, being characteristics of the emitting material. Therefore, Raman spectroscopy is a power tool for identification of bio-analytes. Infrared absorption spectroscopy can also be used for such identification; meanwhile, the broad bands always present in the infrared spectra make difficult a precise identification of the analytes. The usefulness of infrared absorption spectroscopy is even less when is used to detect the presence in blood or urine because of the strong infrared light absorption of the water present in both $[15,16]$.

The main advantages of using Raman spectroscopy over other techniques, like mass spectroscopy and chromatography, is that Raman spectroscopy allow the analysis to be made in real time, could be more precise and low cost.

The aim of this work is to demonstrate that NIRS technique can detect, in vitro, the presence of ephedrine in human urine, as well in rat urine, even for concentrations lower than the doping limit legally permitted by the IOC (International Olympic Committee). That will constitute the first step towards the developing of a practical, ease of use system for a noninvasive doping control in sports.

\section{Materials and methods}

\subsection{Raman spectroscopy system}

The excitation laser source consists of a Ti:Saphire laser (Spectra Physics, model 3900S) pumped by a $6 \mathrm{~W}$ multi-line argon ion laser (Spectra Physics, model 2709S), tuned at $785 \mathrm{~nm}$. The Raman radiation from the sample was collected and coupled into the spectrometer entrance slit by a couple of lenses. The optical detection system was composed by a high coupling spectrograph (Kaiser Optical System, f/1.8i) and a liquid nitrogen cooled CCD, "Deep Depletion" detector (Princeton Instruments, EEV $1024 \times 256$ 


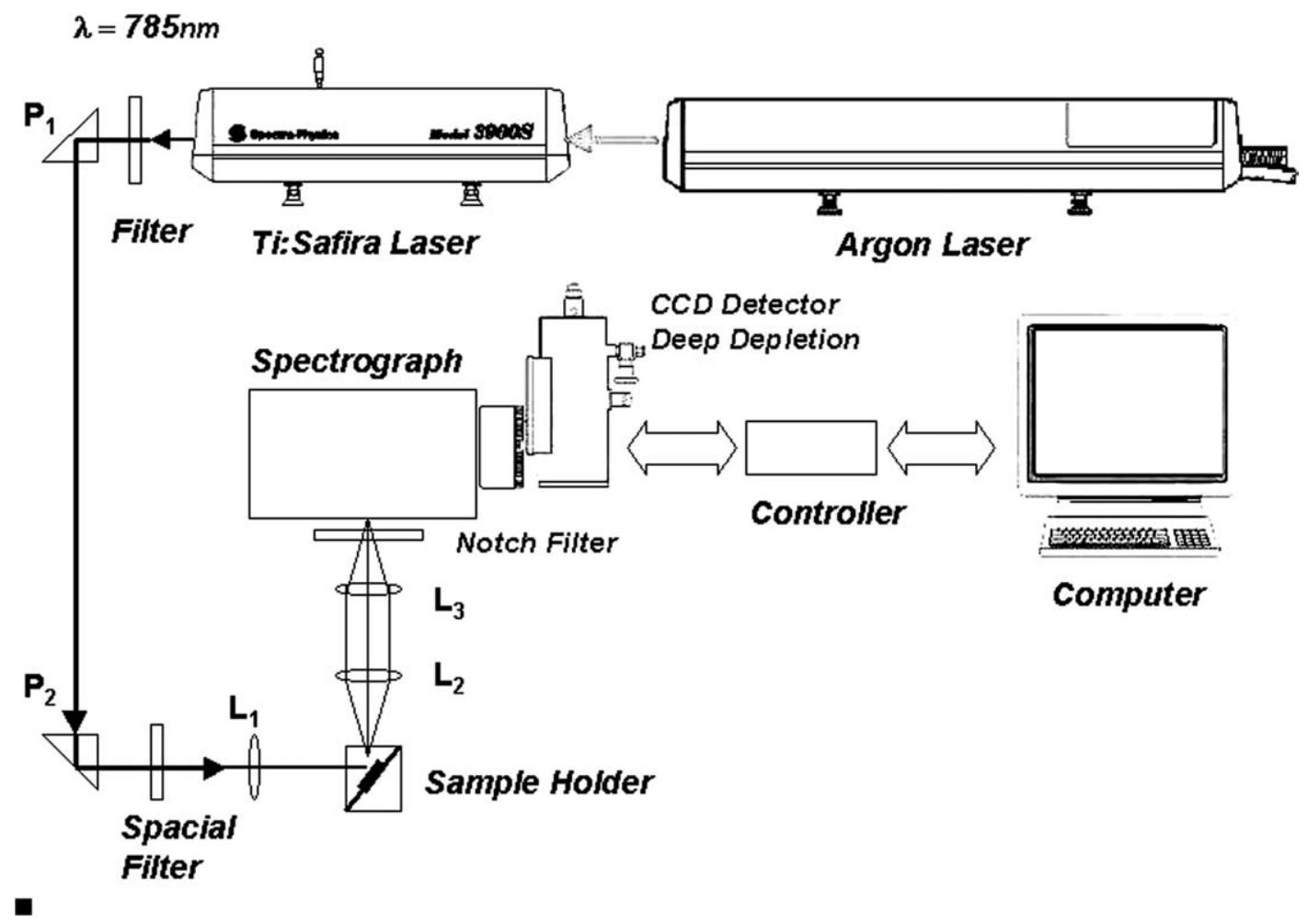

Fig. 1. Schematic diagram of the experimental setup.

pixels) and CCD controller (Princeton Instruments, model 135). The spectrometer resolution, with a $10 \mu \mathrm{m}$ entrance slit width, was estimated to be around $5 \mathrm{~cm}^{-1}$. The detector controller was connected to a personal computer that saves and processes Raman spectra. The intensity of the excitation laser was strongly reduced in the collection system by using a holographic notch filter centered at $785 \mathrm{~nm}$ (Kaiser Optical Systems, model HSPF 785AR2.0).

The optical detection system (spectrometer and CCD detector), was Raman shift calibrated using as a reference an organic compound, the indene $\mathrm{C}_{9} \mathrm{H}_{8}$, with a well-established Raman spectrum that presents intense bands covering the spectral range from 700 to $1700 \mathrm{~cm}^{-1}$. The contribution of the sample fluorescence to the Raman spectra was eliminated by subtracting a third-order fitting polynomium from the gross spectrum.

The samples were placed in a quartz cuvette, facing the spectrometer entrance slit. The pumping laser beam impinged the cuvette forming a right angle with respect to the signal collection optical axis. Urine samples were irradiated with $70 \mathrm{~mW}$ laser power, with a $100 \mathrm{~s}$ total acquisition time for each sample. A schematic diagram of the experimental setup is shown in Fig. 1.

\subsection{Experimental procedure}

Raman spectrum of ephedrine has a set of well-defined peaks. These peaks can be used to identify and calculate the concentration of ephedrine in urine [17]. To establish a curve for calculation of ephedrine concentration in urine, the following steps were undertaken: 
(i) Raman spectra of human urine, obtained by micturation, were taken using the Raman system described above. Spectra were obtained within one hour after micturation and without any pretreatment of the urine. Urine samples from five healthy individuals were collected and their respective Raman spectra were taken. Then, all five spectra were averaged to obtain a standard spectrum for the normal human urine. All subjects signed a Term of Consent after a comprehensive explanation of the experiment.

(ii) Commercial ephedrine hydrochloride $\left(\mathrm{C}_{10} \mathrm{H}_{15} \mathrm{NO} \cdot \mathrm{HCl}\right)$ powder was used though all the experiment, without any extra purification (from Byoformula, SP, Brazil). Five Raman spectra were taken of pure ephedrine powder, fluorescence subtracted and then averaged.

(iii) Ephedrine was added to human urine to obtain a set of solutions at the following concentrations: $4.8 \mu \mathrm{g} / \mathrm{ml}, 12 \mu \mathrm{g} / \mathrm{ml}, 24 \mu \mathrm{g} / \mathrm{ml}, 120 \mu \mathrm{g} / \mathrm{ml}, 600 \mu \mathrm{g} / \mathrm{ml}, 3.8 \mathrm{mg} / \mathrm{ml}, 15 \mathrm{mg} / \mathrm{ml}$ and $75 \mathrm{mg} / \mathrm{ml}$, respectively. Sample volume was $1 \mathrm{ml}$ for all solutions. Five Raman spectra were taken and averaged for each solution. All spectra of ephedrine-added urine were corrected by subtracting the standard human urine spectrum from each of them. So, the contribution of urine to the spectrum was unconsidered. Then, the intensity of most prominent peak of ephedrine was measured for each solution and a calibration curve was obtained by plotting the intensity of Raman peak as a function of the solution concentration.

(iv) After detecting ephedrine by direct addiction to human urine samples, it was verified if the NIRS technique could detect the ephedrine in urine after its metabolization by the organism. It was expected that, since ephedrine is integrally excreted by the urine [25,26], a small amount of it should be observed. To answer that question another experiment was undertaken. For so, $0.5 \mathrm{ml}$ of an ephedrine in saline solution, at the concentration of $5 \mathrm{mg} / \mathrm{ml}$, was injected via subcutaneous into a male Wistar rat weighing $200 \mathrm{~g}$. The rat urine was collected three hours after injection, and then Raman spectra were taken. Animals were cared in accordance with the National Guidelines for the Human Treatment of Laboratory Animals. This study was approved by the Committee of Ethics in Research at the Universidade do Vale do Paraíba - São José dos Campos, SP, Brazil, under protocol number 1169/2004/CEP.

\section{Results}

The Raman spectrum of standard human urine is shown in Fig. 2. It can be observed a strong and sharp Raman peak at $1005 \mathrm{~cm}^{-1}$, and a smaller broad peak at $1615 \mathrm{~cm}^{-1}$, with a FWHM (full width at half maximum) of $52 \mathrm{~cm}^{-1}$. Figure 3 shows the Raman spectrum of ephedrine hydrochloride powder in the spectral range of $600 \mathrm{~cm}^{-1}$ to $1800 \mathrm{~cm}^{-1}$. Several Raman peaks are observed in ephedrine spectrum, located mainly at $618,753,834,910,1002,1025,1173,1208,1334,1390,1462$ and $1603 \mathrm{~cm}^{-1}$. The strongest peak is at $1002 \mathrm{~cm}^{-1}$, followed by strong peaks at 834 and $1603 \mathrm{~cm}^{-1}$. The peak at $1002 \mathrm{~cm}^{-1}$ and the one at around $1600 \mathrm{~cm}^{-1}$ correspond to a strong ring breathing vibration mode and to a phenyl $\mathrm{C}=\mathrm{C}$ stretching vibration mode, respectively. The main peak at $1002 \mathrm{~cm}^{-1}$ was used to detect the presence of ephedrine.

A Raman spectrum of an ephedrine solution in human urine is shown in Fig. 4, without the standard human urine spectrum being subtracted. It corresponds to an ephedrine concentration of $75 \mathrm{mg} / \mathrm{ml}$. The ephedrine peak at $1002 \mathrm{~cm}^{-1}$ is very prominent compared to all other peaks. Low intensity ephedrine's peaks all over the range can also be seen. The human urine peak at $1005 \mathrm{~cm}^{-1}$ is not seen because of the much stronger ephedrine peak at $1002 \mathrm{~cm}^{-1}$. Nevertheless, the broad peak of the human urine located at around $1600 \mathrm{~cm}^{-1}$ can be easily seen.

Figure 5A plots the intensity of Raman peak at $1002 \mathrm{~cm}^{-1}$ for the ephedrine solutions in human urine versus the concentration of ephedrine. As pointed out, the Raman spectrum of normal human 


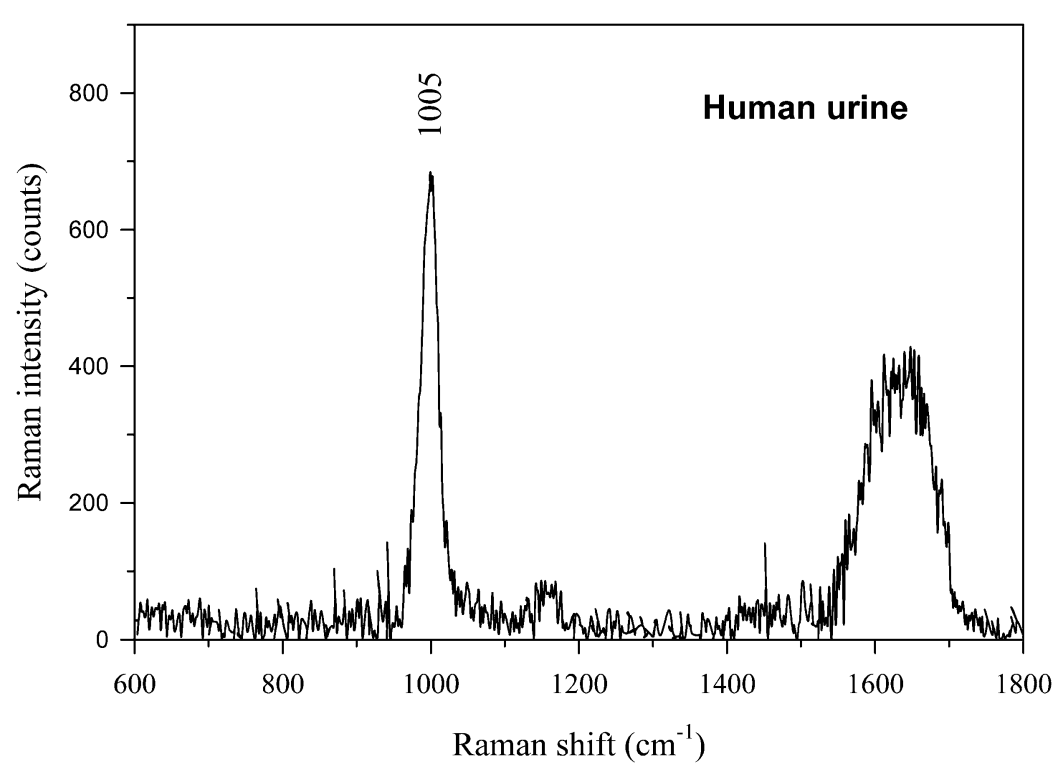

Fig. 2. Raman spectrum of human urine.

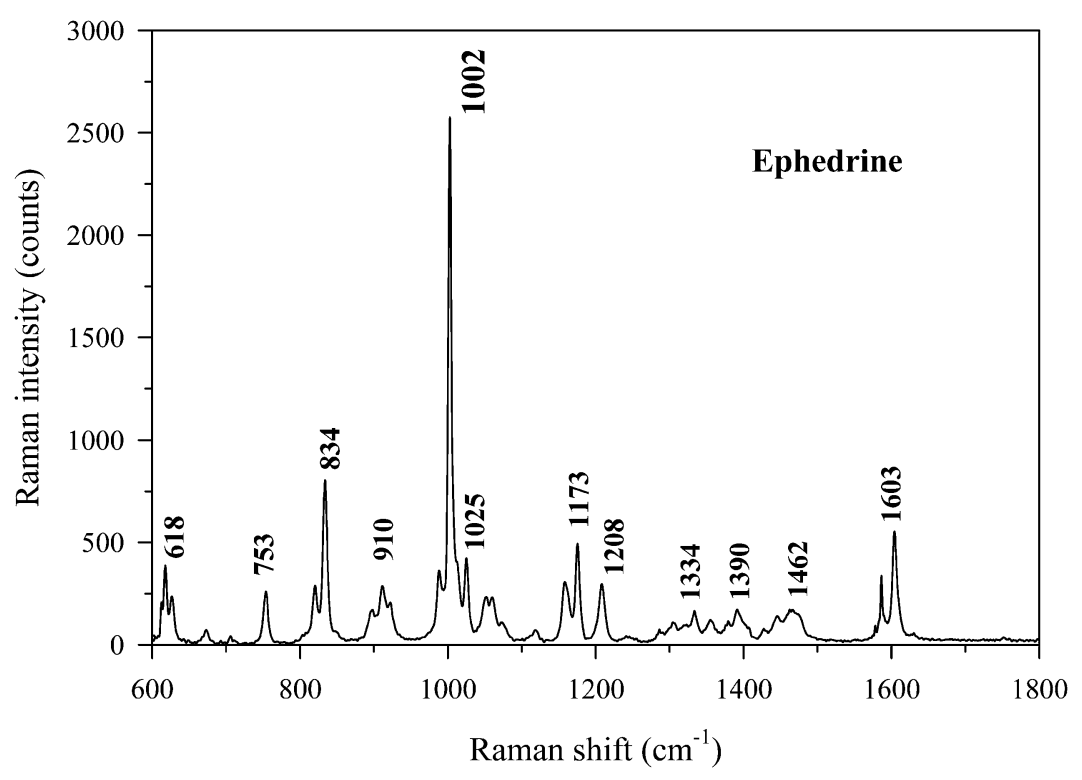

Fig. 3. Raman spectrum of pure ephedrine powder.

urine was subtracted before measuring the peak intensity of ephedrine solutions. Good correlation was obtained between the $1002 \mathrm{~cm}^{-1}$ peak intensity and the ephedrine concentration (correlation coefficient $R=0.998)$. An enlarged plot for the peak intensities for the four lowest ephedrine concentrations is shown in Fig. 5B. In this case it was also found a high correlation coefficient $(R=0.95)$. The minimum concentration of ephedrine detected in urine was $4.8 \mu \mathrm{g} / \mathrm{ml}$.

Raman spectra of human and Wistar rat urine are shown in Fig. 6. Both spectra were normalized to present the same intensity for the strong peak at $1005 \mathrm{~cm}^{-1}$. It can be seen that both spectra are very 


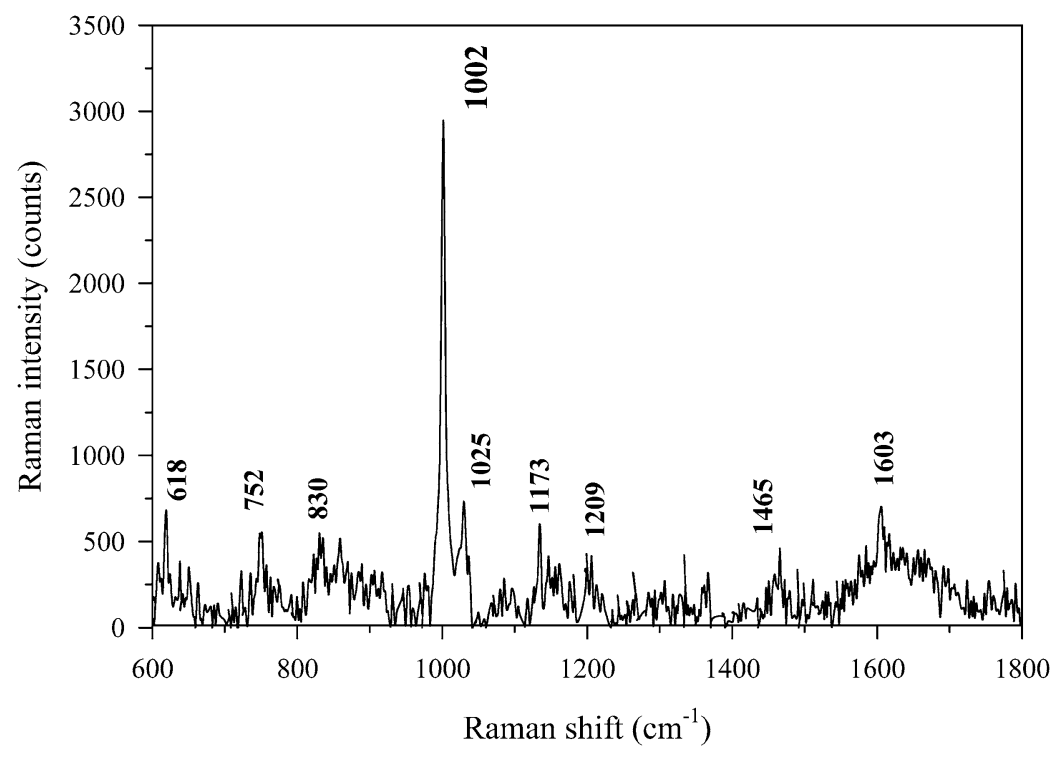

Fig. 4. Raman spectrum of a solution of human urine containing $75 \mathrm{mg} / \mathrm{ml}$ of ephedrine.

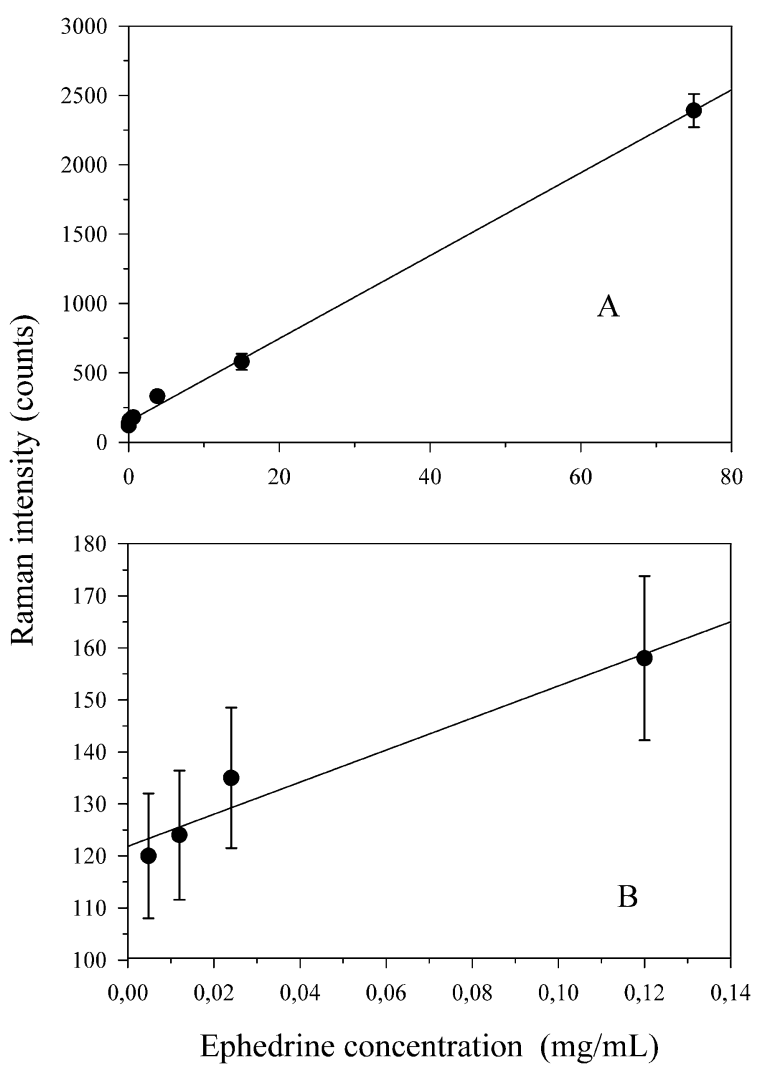

Fig. 5. (A) Raman peak intensity at $1002 \mathrm{~cm}^{-1}$ for the different ephedrine solutions in human urine versus the ephedrine concentration. (B) Raman peak intensity at $1002 \mathrm{~cm}^{-1}$ versus the ephedrine concentration in urine for the four lowest concentrations. 


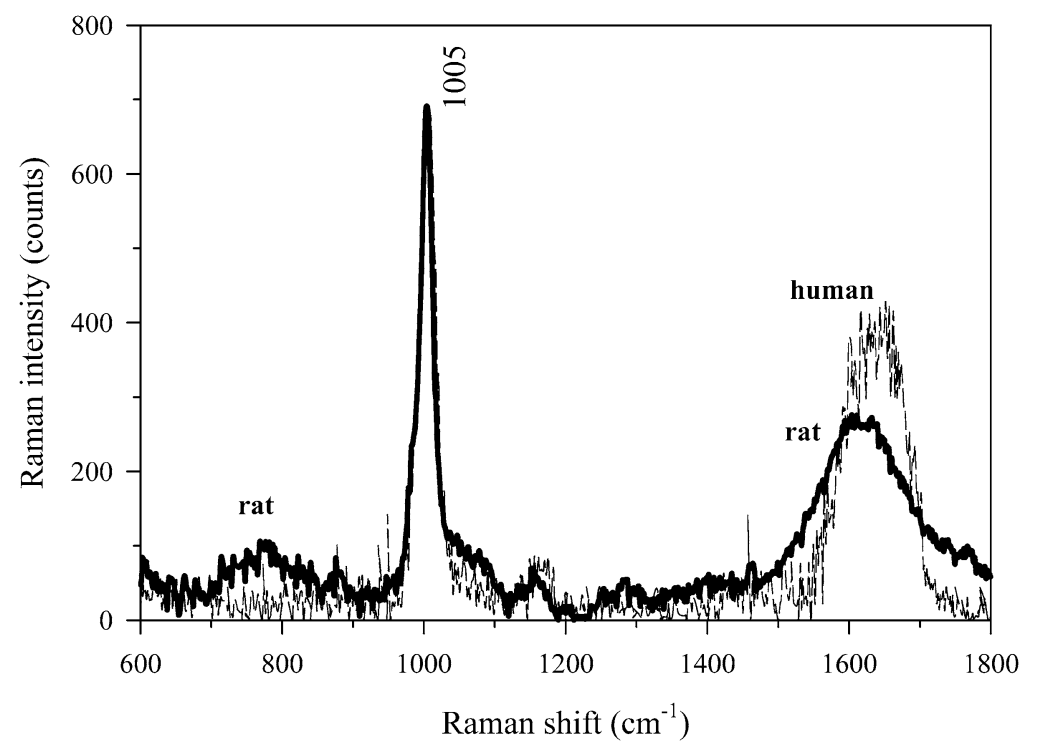

Fig. 6. Comparison between Raman spectra of human and Wistar rat urines.

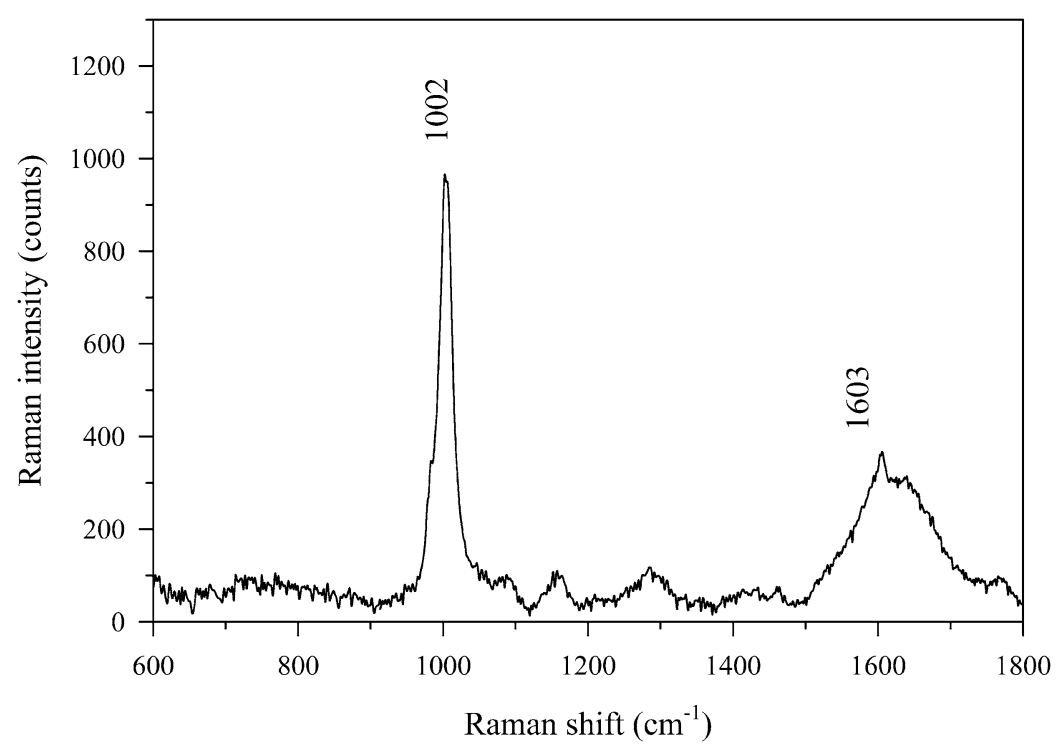

Fig. 7. Raman spectrum of Wistar rat urine after subcutaneous administration of an ephedrine solution in saline solution (concentration of $5 \mathrm{mg} / \mathrm{ml}$ ).

similar, presenting only small differences between them. Figure 7 displays a total Raman spectrum of Wistar rat urine (without rat urine spectrum subtraction) after subcutaneous administration of ephedrine. It is observed again the strong peak at around $1002 \mathrm{~cm}^{-1}$ (from the ephedrine) and the broad peak at around $1600 \mathrm{~cm}^{-1}$ from the urine. Using the normalization between rat and human urine and the calibration curve, shown in Fig. 5A, it is possible to estimate the ephedrine concentration to be $0.57 \mathrm{mg} / \mathrm{ml}$. The calibration relation is given by $I=148+30 C$ where $I$ is the Raman peak intensity (counts) and $C$ is the ephedrine concentration $(\mathrm{mg} / \mathrm{ml})$. 


\section{Discussion}

Biological fluids, like urine, usually emit strong fluorescence [18]; so, for best signal-to-noise ratio, the excitation wavelength for Raman scattering experiments should be the near-infrared. At that wavelength, the background fluorescence is strongly reduced. For so, we chose a Ti:Saphire laser tuned at $785 \mathrm{~nm}$, with laser power of $70 \mathrm{~mW}$ at the sample position.

Raman spectra from urine samples are expected to vary significantly among different persons, as well as a function of time. Therefore, several Raman spectra of human urine from different subjects and at different times (earlier than one hour after urine collection) were taken, fluorescence background subtracted and then, all averaged. This average spectrum was used as the human urine Raman spectrum standard.

The lower ephedrine concentration that was analyzed in our experiment was $4.8 \mu \mathrm{g} / \mathrm{ml}$. At this low concentration, the Raman peak at $1002 \mathrm{~cm}^{-1}$ presents a signal-to-noise ratio of the order of ten; that indicates that it will be possible to detect even lower concentrations of ephedrine in urine, without the necessity of using multivariate statistical analysis (PLS method). No lower concentrations were investigated, since a concentration of $4.8 \mu \mathrm{g} / \mathrm{ml}$ corresponds to half of doping limit in sports, that is $10 \mu \mathrm{g} / \mathrm{ml}$.

Because of the proximity between the spectral position of the Raman peaks of the ephedrine and the urine, the width of the spectrometer entrance slit was set to $10 \mu \mathrm{m}$, giving a spectral resolution of about $5 \mathrm{~cm}^{-1}$. That reduction of the slit width had the drawback to reduce the signal to noise ratio, even so, it was possible to detect ephedrine concentrations as low as $4.8 \mu \mathrm{g} / \mathrm{ml}$.

Rat experiment was done to investigate the possibility of detecting low concentration of ephedrine in urine, after the ephedrine metabolization by a living organism. Rat and human urine Raman spectra present no significant differences when compared to each other. Then, it was used the main peak at $1005 \mathrm{~cm}^{-1}$ for the intensity normalization between both spectra. Using the curve of peak intensity versus ephedrine concentration it was possible to quantify the concentration of ephedrine in the rat urine $(0.57 \mathrm{mg} / \mathrm{ml})$.

NIRS technique can also be extended to detect other drugs considered by the IOC as doping. Results with ephedrine indicate that a dedicated Raman system can be developed for the quantitative analysis of prohibited drugs. The main advantages of the NIRS technique are the possibly to built a compact system for a real time diagnosis and a remote monitoring system at an affordable price.

The choice of which part of human body could be used for noninvasive spectroscopic blood monitoring of athletes is a critical factor and more studies are needed. The index finger [19,20], the inner portion of the lower lip [21,22], the forearm [23], and the webbing tissue between the thumb and forefinger [24] have been proposed for noninvasive measurements with NIRS. Ocular measurements have also been suggested [9]. The chemical and physical properties of the measurement site are also critical because they influence, and even may determine, the overall signal-to-noise ratio of the measurement.

\section{Conclusion}

Results indicate that it is possible to measure, in vitro, the ephedrine concentration in urine by using the NIRS technique, allowing the detection of concentrations lower than the doping limit legally permitted by the International Olympic Committee. 


\section{Acknowledgements}

The authors are grateful to PADCT/FINEP, CNPq, CAPES and FAPESP for the financial support. A.E. Guimarães acknowledges the research fellowship from CAPES.

\section{References}

[1] A.M. Bohn, M. Khodaee and T.1. Schwenk, Ephedrine and other stimulants as ergogenic aids, Curr. Sports Med. Rep. 2 (2003), 220-225.

[2] F.R. Aquino Neto, O papel do atleta na sociedade e o controle de dopagem no esporte, Rev. Bras. Med. Esporte 7 (2001), 4-9.

[3] E.H. de Rose, M.G. Feder, R.M.A. Bento and F.R. Aquino Neto, Informações sobre o uso de medicamentos no esporte. Comitê Olímpico Brasileiro. Departamento Médico, $4^{\mathrm{a}}$ Ed., Rio de Janeiro, 2004.

[4] R.L. Dupont and W.A. Baumgartner, Drug testing by urine and hair analysis complementary features and scientific issues, Forensic. Sci. Int. 70 (1995), 63-76.

[5] R.L. Hawks and C.N. Chiang, Urine Testing for Drugs of Abuse, U.S. Department of Health and Human Services, National Institute on Drug Abuse, Research Monograph 73, Rockville, MD, 1986.

[6] O.S. Khalil, Spectroscopic and clinical aspects of noninvasive glucose measurements, Clinical Chemistry 45 (1999), 165177.

[7] G.L. Coté and B.D. Cameron, Noninvasive polarimetric measurement of glucose in cell culture media, J. Biomed. Opt. 2 (1997), 275-281.

[8] G.L. Coté, Noninvasive and minimally-invasive optical monitoring technologies, Journal of Nutrition 13 (2001), 1596S$1604 \mathrm{~S}$.

[9] B.D. Cameron, H.W. Gorde, B. Satheesan and G.L. Coté, The use of polarized laser light through the eye for noninvasive glucose monitoring, Diabetes Technol. Ther. 1 (1999), 135-143.

[10] J.P. Xie, J.Y. Zhang, J.Q. Liu, J.N. Tian, X.G. Chen and Z.D. Hu, Micellar electrokinetic chromatography with laserinduced fluorescence detection for sensitive determination of ephedrine and pseudoephedrine, J. Separation Sci. 27 (2004), $1211-1214$.

[11] G.S. Yu, D.P. Che, T.B. Freedman and L.A. Nafie, Backscattering dual circular-polarization Raman optical-activity in Ephedrine molecules, Tetrahedron-Asymmetry 4 (1993), 511-516.

[12] H. Tsuchihashi, M. Katagi, M. Nishikawa, M. Tatsuno, H. Nishioka, A. Nara, E. Nishio and C. Petty, Determination of methamphetamine and its related compounds using Fourier transform Raman spectroscopy, Appl. Spectr. 51 (1997), $1796-1799$.

[13] A.D. Shaw, N. Kaderbhai, A. Jones, A.M. Woodward, R. Goodacre, J.J. Rowland and D.B. Kell, Noninvasive, on-line monitoring of the biotransformation by yeast of glucose to ethanol using dispersive Raman spectroscopy and chemometrics, Appl. Spectrosc. 53 (1999), 1419-1428.

[14] S. Pilotto, M.T.T. Pacheco, L. Silveira Jr., A.B. Villaverde and R.A. Zângaro, Analysis of Near-Infrared Raman Spectroscopy as a new technique for a transcutaneous non-invasive diagnosis of blood components, Lasers Med. Sci. 16 (2001), $2-9$.

[15] H. Chung, M.A. Arnold, M. Rhiel and D.W. Murhammer, Simultaneous measurements of glucose, glutamine, ammonia, lactate, and glutamate in aqueous solutions and aqueous humor specimens, Appl. Spectrosc. 50 (1996), 270-276.

[16] R. Vonach, J. Buschmann, R. Falkowski, R. Schindler, B. Lendl and R. Kellner, Application of mid-infrared transmission spectrometry to direct determination of glucose in whole blood, Appl. Spectrosc. 52 (1998), 820-822.

[17] G. Trachta, B. Schwarze, B. Sägmüller, G. Brehm and S. Schneider, Combination of high-performance liquid chromatography and SERS detection applied to the analysis of drugs in human blood and urine, Journal of Molecular Structure $\mathbf{6 9 3}$ (2004), 175-185.

[18] X. Dou, Y. Yamaguchi, H. Yamamoto, S. Doi and Y. Ozaki, A highly sensitive compact Raman system without a spectrometer for quantitative analysis of biological samples, Vib. Spectrosc. 14 (1997), 199-205.

[19] K. Jagemann, C. Fischbacher, K. Danzer, U.A. Müller and B. Mertes, Application of near-infrared spectroscopy for noninvasive determination of blood/tissue glucose using neural networks, Z. Phys. Chem. 191 (1995), 179-190.

[20] M.R. Robinson, R.P. Eaton, D.M. Haaland, G.W. Koepp, E.V. Thomas, B.R. Stallard and R.L. Robinson, Noninvasive glucose monitoring in diabetic patients: a preliminary evaluation, Clin. Chem. 38 (1992), 1618-1622.

[21] R. Marbach, T.H. Koschinsky, F.A. Gries and H.M. Heise, Noninvasive blood glucose assay by near-infrared diffuse reflectance spectroscopy of the human inner lip, Appl. Spectrosc. 47 (1993), 875-881.

[22] H.M. Heise, Non-invasive monitoring of metabolites using near infrared spectroscopy: state of the art, Horm. Metab. Res. 28 (1996), 527-534. 
[23] S.F. Malin, T.L. Ruchti, T.B. Blank, S.N. Thennadil and S.L. Monfre, The noninvasive measurement of glucose by nearinfrared diffuse reflectance spectroscopy, Clin. Chem. 45 (1999), 1651-1658.

[24] K.H. Hazen, Glucose determination in biological matrices using near-infrared spectroscopy, PhD Dissertation, University of Iowa, Iowa City, IA, 1995.

[25] G. Goodman, in: The Pharmacological Basis of Therapeutics, McGraw-Hill, 9th ed., 1996, p. 221.

[26] W. Martindale, in: The Extra Pharmacopoeia, 27 ed., The Pharmaceutical Press, London, 1977. 


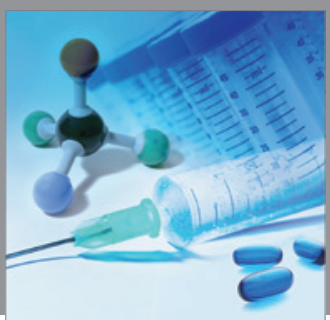

International Journal of

Medicinal Chemistry

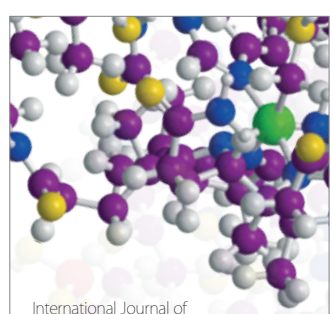

Carbohydrate Chemistry

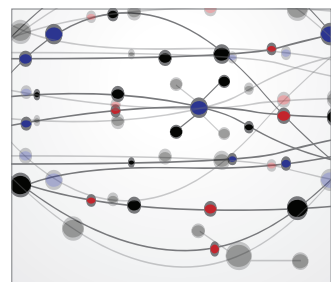

The Scientific World Journal
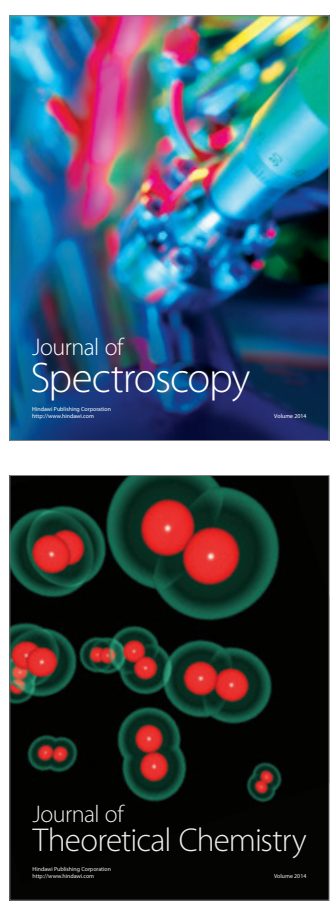
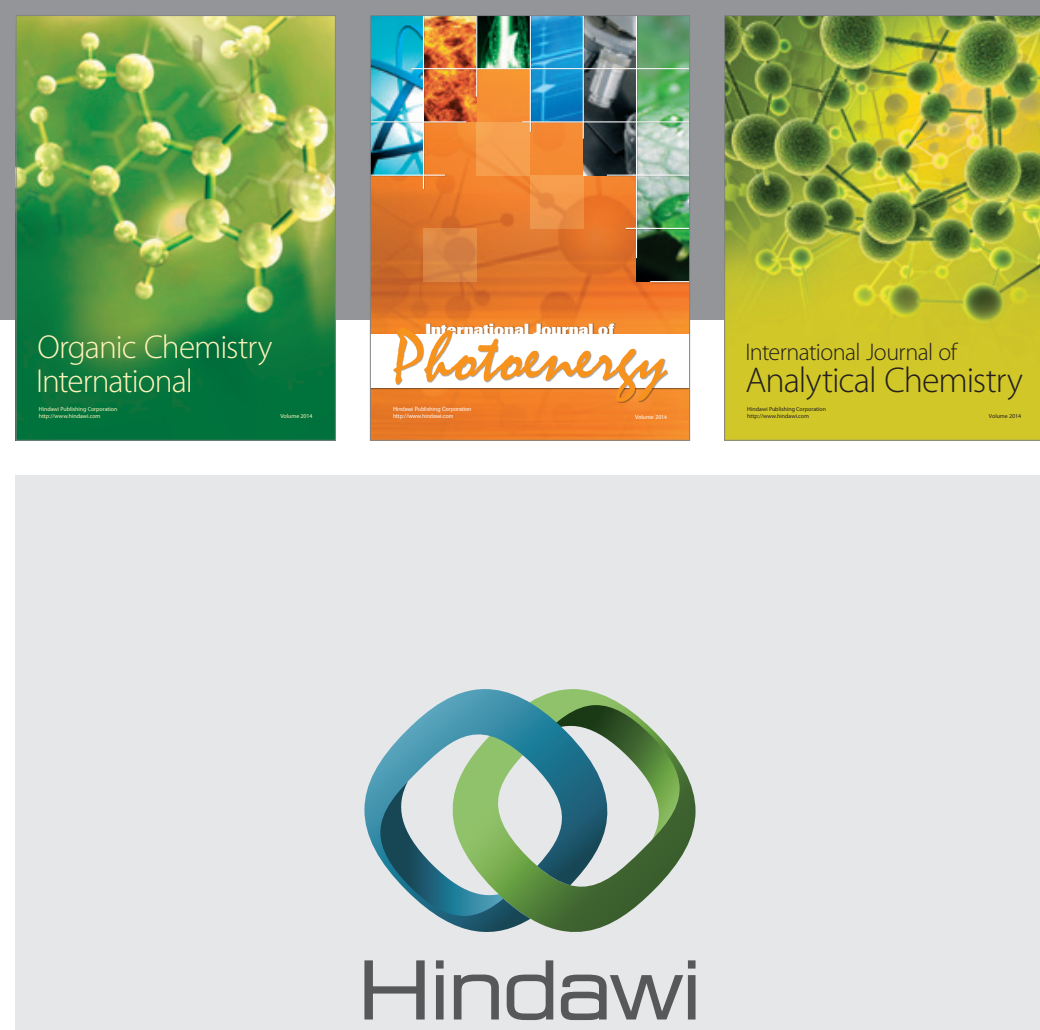

Submit your manuscripts at

http://www.hindawi.com
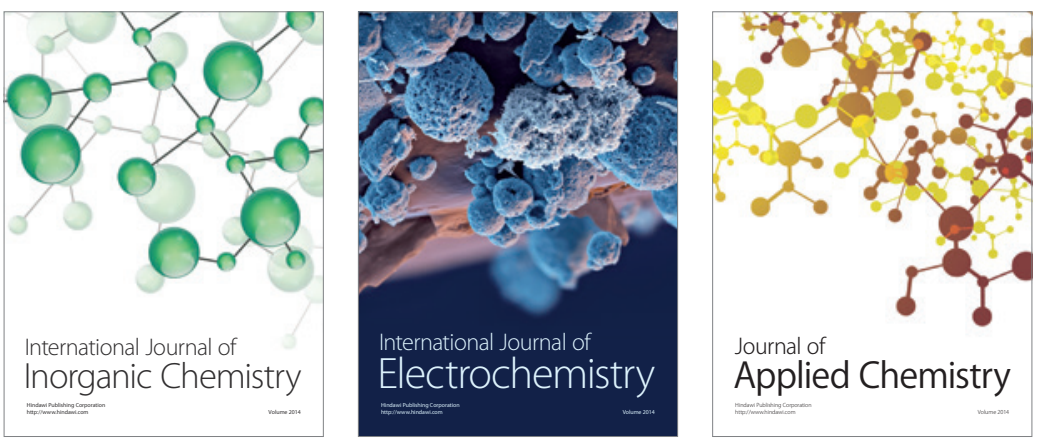

Journal of

Applied Chemistry
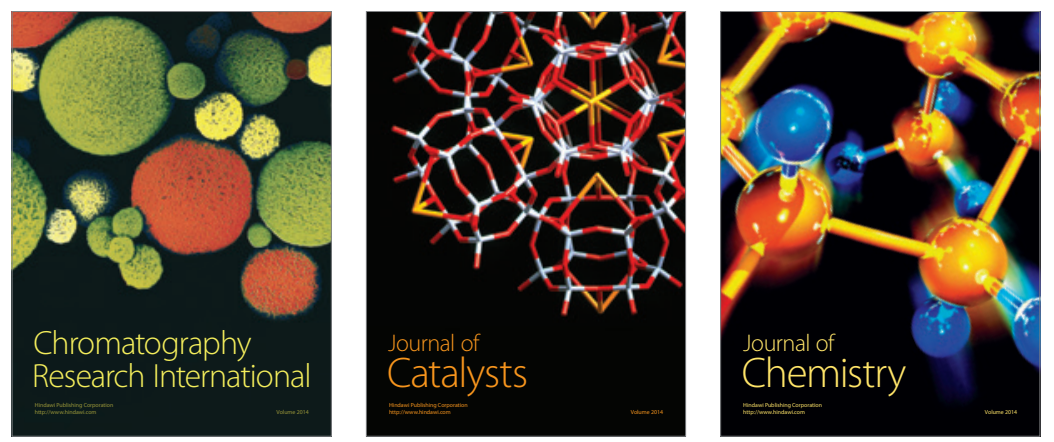
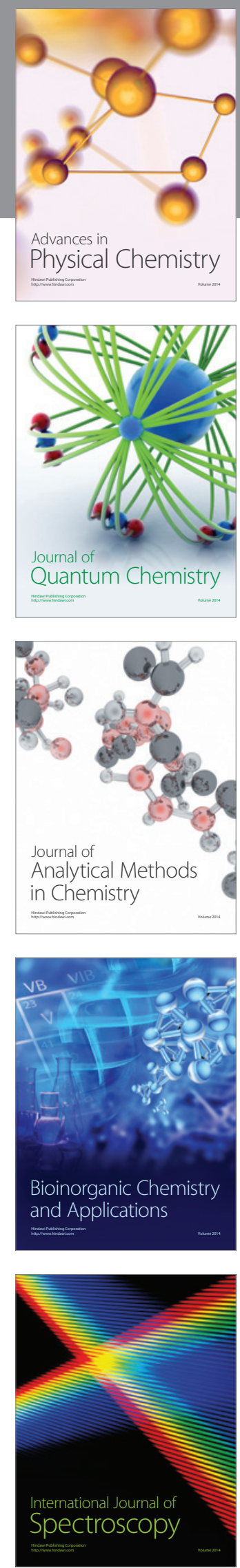